Table 1. Baseline characteristics by cohort

\begin{tabular}{|l|c|c|c|}
\hline & $\begin{array}{c}\text { ABA } \\
(\mathrm{n}=20,410)\end{array}$ & $\begin{array}{c}\text { TOF } \\
(\mathrm{n}=5048)\end{array}$ & $\begin{array}{c}\text { TOC } \\
(\mathrm{n}=5098)\end{array}$ \\
\hline Age, years, mean (SD) & $55.4(12.6)$ & $55.1(11.7)$ & $54.2(13.1)^{*}$ \\
\hline Female, $\mathrm{n}(\%)$ & $16,784(82.2)$ & $4123(81.7)$ & $4107(80.6)^{*}$ \\
\hline TNF-experienced, $\mathrm{n}(\%)$ & $10,171(49.8)$ & $2431(48.2)^{*}$ & $2895(56.8)^{*}$ \\
\hline CS use, $\mathrm{n} \%)$ & $12,167(59.6)$ & $3379(66.9)^{*}$ & $3148(61.7)^{*}$ \\
\hline CCI score, mean (SD) & $1.4(1.0)$ & $1.4(0.9)$ & $1.4(1.0)$ \\
\hline COPD/asthma & $282(1.4)$ & $123(2.4)^{*}$ & $103(2.0)^{*}$ \\
\hline Pneumonia & $661(3.2)$ & $131(2.6)^{*}$ & $158(3.1)$ \\
\hline Pulmonary nodule & $437(2.1)$ & $182(3.6)^{*}$ & $185(3.6)^{*}$ \\
\hline Heart failure & $623(3.1)$ & $107(2.1)^{*}$ & $132(2.6)$ \\
\hline Dyslipidaemia & $3185(15.6)$ & $926(18.3)^{*}$ & $951(18.7)^{*}$ \\
\hline $\begin{array}{l}\text { Ischaemic heart } \\
\text { disease }\end{array}$ & $1448(7.1)$ & $324(6.4)$ & $307(6.0)^{*}$ \\
\hline Osteoarthritis & $5623(27.6)$ & $1648(32.6)^{*}$ & $1594(31.3)^{*}$ \\
\hline Lupus & $929(4.6)$ & $148(2.9)^{*}$ & $169(3.3)^{*}$ \\
\hline Infections & $9347(45.8)$ & $2196(43.5)^{*}$ & $2300(45.1)$ \\
\hline $\begin{array}{l}\text { *p<0.05 vs ABA } \\
\text { ABA=abatacept; CCl=Charlson Comorbidity Index; COPD=chronic obstructive pulmonary disease; } \\
\text { CS=corticosteroid; TOC=tocilizumab; TOF=tofacitinib }\end{array}$ \\
\hline \multicolumn{4}{|l}{}
\end{tabular}

Table 2. Persistence by cohorts: overall and stratified by prior TNF and CS use

\begin{tabular}{|c|c|c|c|}
\hline & ABA & TOF & TOC \\
\hline Overall & $\begin{array}{c}n=20,410 \\
337.9(416.8) \\
191\end{array}$ & $\begin{array}{c}\mathrm{n}=5046 \\
257.3(288.0)^{*} \\
151\end{array}$ & $\begin{array}{c}\mathrm{n}=5098 \\
294.0(345.1)^{*} \\
168\end{array}$ \\
\hline TNF-naïve & $\begin{array}{c}n=10,239 \\
328.1(409.7) \\
179\end{array}$ & $\begin{array}{c}n=2616 \\
252.9(285.3)^{*} \\
146\end{array}$ & $\begin{array}{c}n=2203 \\
276.7(341.2)^{*} \\
148\end{array}$ \\
\hline TNF-experienced & $\begin{array}{c}n=10,171 \\
347.7(423.7) \\
201\end{array}$ & $\begin{array}{c}\mathrm{n}=2430 \\
262.1(290.9)^{*} \\
159\end{array}$ & $\begin{array}{c}n=2895 \\
307.2(347.6)^{*} \\
178\end{array}$ \\
\hline CS-naïve & $\begin{array}{c}n=8243 \\
333.0(415.1) \\
186\end{array}$ & $\begin{array}{c}n=1668 \\
263.4(289.6)^{*} \\
160\end{array}$ & $\begin{array}{c}n=1950 \\
288.7(335.8)^{*} \\
165\end{array}$ \\
\hline CS-experienced & $\begin{array}{c}\mathrm{n}=12,167 \\
341.1(418) \\
194\end{array}$ & $\begin{array}{c}n=3378 \\
254.3(287.3)^{*} \\
148\end{array}$ & $\begin{array}{c}\mathrm{n}=3148 \\
297.3(350.8)^{*} \\
169\end{array}$ \\
\hline \multicolumn{4}{|c|}{$\begin{array}{l}\text { Values are expressed as mean (SD) median, in days reported } \\
\text { " } p<0.05 \text { vs } A B A \\
A B A=\text { abatacept; } C S=\text { corticosteroid; } T O C=\text { tocilizumab; TOF=tofacitinib }\end{array}$} \\
\hline
\end{tabular}

Disclosure of Interests: Leticia Ferri Shareholder of: Bristol-Myers Squibb, Employee of: Bristol-Myers Squibb, Evo Alemao Shareholder of: BristolMyers Squibb, Employee of: Bristol-Myers Squibb, Sonie Lama Employee of: Bristol-Myers Squibb, Aarti Rao Consultant for: Bristol-Myers Squibb DOI: 10.1136/annrheumdis-2019-eular.1468

\section{SAT0087 REAL-LIFE GOLIMUMAB PERSISTENCE IN PATIENTS WITH CHRONIC INFLAMMATORY RHEUMATIC DISEASES: FINAL RESULTS OF THE GO-PRACTICE STUDY}

René-Marc Flipo ${ }^{1}$, Florence Tubach ${ }^{2}$, Jean Ouaniche ${ }^{3}$, Philippe Goupille ${ }^{4}$ Eric Lespessailles $^{5}$, Najat Gouyette ${ }^{6}$, Naoual Harid ${ }^{6}$, Saannya Sequeira ${ }^{7}$, Philippe Bertin ${ }^{8}$, Bruno Fautrel ${ }^{2} .{ }^{1}$ University hospital of Lille, LILLE, France; ${ }^{2}$ Pitié Salpétrière University Hospital, PARIS, France; ${ }^{3}$ Private practice Toulon, TOULON, France; ${ }^{4}$ University hospital of Tours, TOURS, France; ${ }^{5}$ Hospital of Orléans, Orléans, France; ${ }^{6}$ MSD France, Courbevoie, France; ${ }^{7}$ Clinsearch, Malakoff, France; ${ }^{8}$ University Hospital of Limoges, Limoges, France

Background: Golimumab (GLM) is the fifth, most recent anti-TNF $\alpha$ to be indicated in the treatment of chronic inflammatory rheumatic diseases. GO-PRACTICE aimed to assess GLM use in real-life clinical practice, in patients with rheumatoid arthritis (RA), psoriatic arthritis (PsA), and axial spondyloarthritis (AS)

Objectives: Primary objective was to assess the persistence of GLM over 2 years after initial prescription. Cumulative persistence probabilities were estimated with the Kaplan-Meier method. Secondary objectives included evaluations of: 1) clinical disease activity from inclusion to 2 years (with DAS28 for RA and PSA; ASDAS for AS); 2) change in patient reported evaluations of pain (VAS [0-100]), disease activity (RAPID3 for RA and PsA; BASDAI for AS), functional ability (HAQ) and quality of life (EQ-5D and SF-12); 3) GLM clinical safety.

Methods: Observational, prospective, multicenter French study. Patients $\geq 18$ years with RA, PsA and AS were included consecutively, following GLM initiation and were followed-up for 2 years. Data were collected at baseline (BL), year 1 and year 2 .
Results: 770 patients selected from January 2015 to March 2016 at 134 sites, of which 754 included in the analysis. Mean age was 46 years and $61 \%$ were female. Most had AS (63\%), followed by RA (23\%) and PsA (14\%). Mean duration of rheumatic disease was 7.6 years and $37 \%$ had previously received biologics; the proportion of patients who received $1,2,3$ and $>4$ biologics were $18 \%, 11 \%, 6 \%$ and $2 \%$, respectively. Most patients were prescribed 50mg GLM monthly (97\%). Concomitant treatments included disease-modifying anti-rheumatic drugs $(38 \%)$, corticosteroids (19\%) and NSAIDs/analgesics (71\%).

Persistence of GLM at 2 years was $52.4 \%$ (56.5\%, $45.1 \%$ and $52.6 \%$ for RA, PsA and AS respectively), and in the AS group was higher for biologics naïve than biologics pretreated patients $(59.2 \%$ vs. $42.7 \%, P<.01)$. Disease activity showed clinically significant improvements from $B L$ to 2 years in persisting patients. For RA, mean DAS28-CRP from $4.3 \pm 1.1$ to $2.3 \pm 0.8(P<.0001)$, mean RAPID3 from $4.5 \pm 1.8$ to $1.8 \pm 1.7(P<.0001)$. For PsA, mean DAS28-CRP from $3.9 \pm 1.0$ to $2.0 \pm 0.8 \quad(P<.0001)$, mean RAPID3 from $5.3 \pm 1.4$ to $2.8 \pm 2.2(P<.0001)$. For AS, mean ASDAS-CRP from $3.2 \pm 0.8$ to $1.7 \pm 1.0 \quad(P<.0001)$, mean BASDAl from $5.5 \pm 1.6$ to 2.8 $\pm 1.9,(P<.0001)$. Pain, HAQ, EQ-5D and SF-12 also improved significantly over 2 years.

During the study, 67 (8.9\%) patients discontinued GLM due to intolerance or adverse event $(\mathbf{A E})$; reported $A E s$ were consistent with GLM's known safety profile. Post-hoc multivariate analyses with sociodemographic and medical history variables showed that for GLM discontinuation over the 2 years, gastrointestinal disease was a risk factor in RA patients [HR 3.9, CI95\% (2.0-7.6)] and being female was a risk factor in AS patients [HR 1.9, Cl95\% (1.4-2.6)]. GLM was re-prescribed for 338 (93.4\%) of 362 patients who persisted on GLM at 2 years.

Conclusion: GLM persistence in real-life is satisfactory at 2 years and accompanied by clinical improvements in RA, PsA and AS patients.

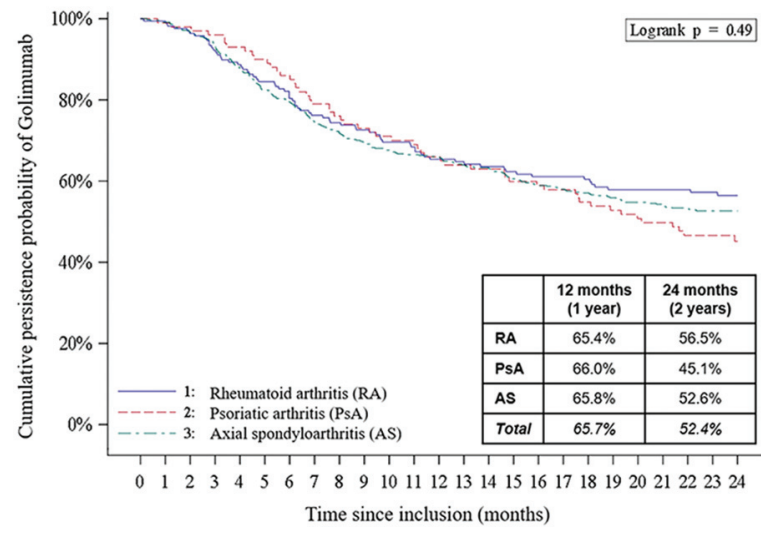

Disclosure of Interests: René-Marc Flipo Consultant for: Honoraria from Novartis as steering committe of this survey, Florence Tubach Grant/ research support from: Financial compensation received from MSD on a pro-rota basis for participation in Scientific Committee meetings and functions for this study, Jean OUANICHE Grant/research support from: Financial compensation received from $\mathrm{MSD}$ on a pro-rota basis for active participation in Scientific Committee meetings and functions, Philippe Gou pille Grant/research support from: Financial compensation received from MSD on a pro-rota basis for participation in Scientific Committee meetings and functions for this study, Speakers bureau: Abbvie, Biogaran, BMS, Hospira, Janssen, MSD, Pfizer, Sanofi-Genzyme, UCB, Eric Lespes sailles Grant/research support from: Grants/research support from Amgen, Eli Lily, MSD, UCB., Consultant for: Consultant for Amgen, Expanscience, Eli Lilly, MSD, UCB., Najat Gouyette Employee of: MSD, France, Naoual HARID Employee of: MSD, France, Saannya Sequeira Consultant for: Contract Research Organization - ClinSearch, Philippe Bertin Grant research support from: Financial compensation received from MSD on a pro-rota basis for participation in Scientific Committee meetings and functions for this study, Bruno Fautrel Grant/research support from: AbbVie, Lilly, MSD, Pfizer, Consultant for: AbbVie, Biogen, BMS, Celgene, Janssen, Lilly, Medac, MSD, NORDIC Pharma, Novartis, Pfizer, Roche Sanofi-Aventis, Sanofi Genzyme, SOBI, UCB DOI: 10.1136/annrheumdis-2019-eular.5686 